\title{
Coronary artery-left ventricular fistula and multiple ventricular septal defects due to blunt chest trauma
}

\author{
A RENZULLI, C WREN, C J HILTON
}

From the Regional Cardiothoracic Department, Freeman Hospital, Newcastle upon Tyne

\begin{abstract}
A 27 year old man developed multiple ventricular septal defects and a coronary artery ventricular fistula after a blunt injury. These were treated successfully by surgery, which was carried out four months after the injury to allow some healing of the defect to occur.
\end{abstract}

Many different cardiac injuries caused by blunt chest trauma have been reported. Multiple ventricular septal defects are an uncommon complication and coronary artery ventricular fistula is rare. The basis of this report is a combination of these lesions, which have not to our knowledge previously been reported.

Address for reprint requests: $\mathrm{Mr} \mathrm{C}$ J Hilton, Regional Cardiothoracic Department, Freeman Hospital, Newcastle upon Tyne NE7 7DN.

Accepted 20 July 1989

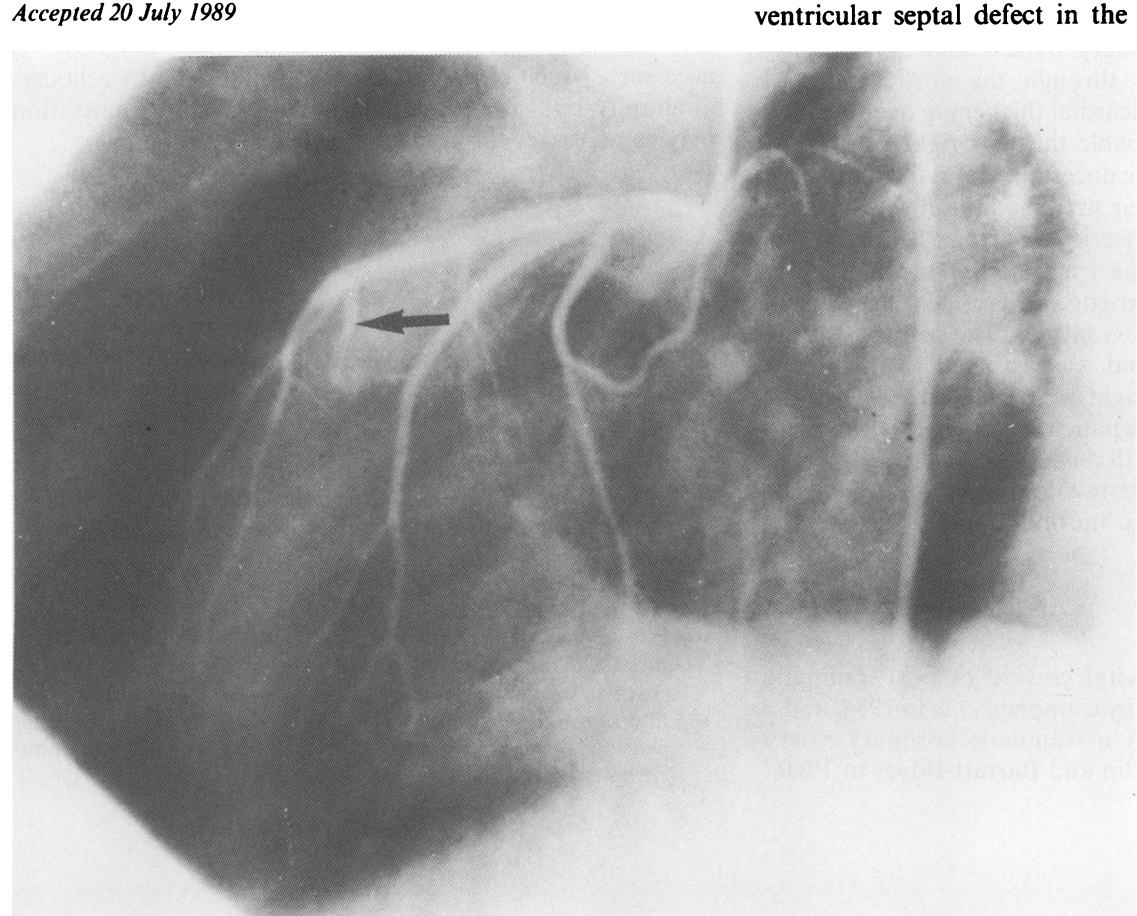

Fig 1 Left coronary angiogram, showing a septal artery-left ventricular fistula (arrow).

A 27 year old man was admitted as an emergency to another hospital in May 1987 with haemoptysis and haematuria after being severely assaulted, knocked to the ground, and kicked on the chest and back. He was noted to be febrile and to have a loud pansystolic murmur. No cardiac murmur had been heard at a medical examination in 1985. An echocardiogram suggested a ventricular septal defect so he was transferred to the Freeman Hospital. On admission he was afebrile and was not cyanosed. His pulse was 80 beats/min and regular and his blood pressure $100 / 74 \mathrm{~mm} \mathrm{Hg}$. There was a prominent systolic thrill at the left sternal edge, a grade $4 / 4$ pansystolic murmur, a normally split second heart sound, and an apical mid diastolic murmur. There were no other findings of note and no evidence of heart failure. Chest radiography showed the heart to be of normal size with some prominence of the upper lobe vessels. The electrocardiogram showed sinus rhythm with a large $P$ wave and loss of the $R$ wave from $V 1$ to V3. A repeat echocardiogram confirmed a large trabecular ventricular septal defect in the muscular septum. Cardiac 


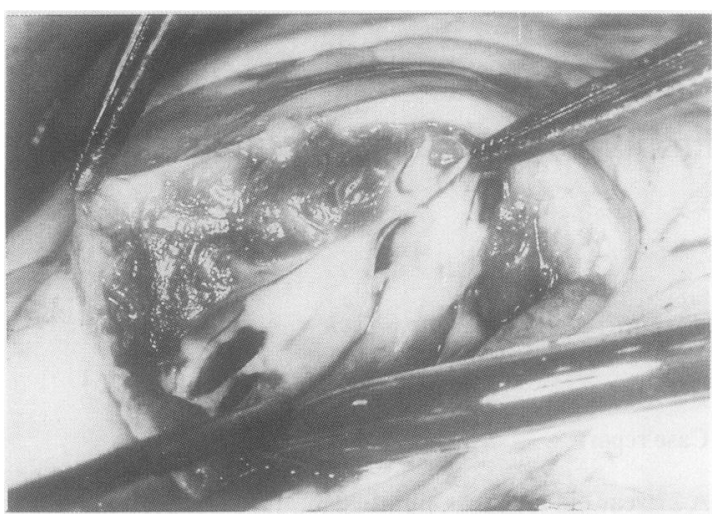

Fig 2 Intraoperative view, showing multiple ventricular septal defects.

catheterisation showed a large irregular ventricular septal defect with a double image on the left ventricular side suggesting a flap of tissue. The pulmonary:systolic blood flow ratio was $3: 1$, pulmonary artery pressure $45 / 20 \mathrm{~mm} \mathrm{Hg}$, and aortic pressure $85 / 60 \mathrm{~mm} \mathrm{Hg}$. Selective coronary angiography showed a fistula from a septal branch of the left anterior descending artery to the left ventricle (fig 1) immediately beyond the second diagonal branch. There was no other coronary artery disease. He was referred for surgery, but because he was haemodynamically well this was deferred to allow some healing of the defect to facilitate the repair. Surgery was carried out four months after the initial presentation.

Surgery was performed through a median sternotomy with normothermic cardiopulmonary bypass and St Thomas's cardioplegic solution given through the aortic root. At operation there was some epicardial thickening over the high anterior septum with a palpable thrill. A right ventricular approach was used as we were uncertain about the number of defects in the septum and their size; in addition, we hoped to gain a clear view of the arterioventricular fistula. Three ventricular septal defects, one $1 \mathrm{~mm}$ across and two about 7-10 mm across with scarred edges, were identified (fig 2). They were closed with mattress sutures. The coronary artery fistula could not be seen and was assumed to have been included in the repair. The right ventriculotomy was closed with continuous prolene. The patient recovered well and was discharged home on the eighth postoperative day.

At follow up six weeks after discharge there was no cardiac murmur and only a systolic murmur grade $1 / 6$ over the pulmonary artery.

\section{Discussion}

The first report of a successful closure of post-traumatic ventricular septal defect was by Campbell et al in 1954' and a successful surgical repair of a traumatic coronary artery fistula was reported by Kirklin and Barratt-Boyes in $1960{ }^{2}$
Clinical experience and necropsy studies have documented $\stackrel{x}{ }$ various lesions that may develop after blunt trauma of the chest. Pericardial effusions, septal defects, valve rupture, and $\stackrel{\oplus}{+}$ myocardial lesions ranging from myocardial contusion to음 cardiac rupture and ventricular aneurysm have been re- $\overline{\bar{V}}$ ported. ${ }^{34}$ The association of multiple ventricular septal $\frac{\mathcal{D}}{\partial}$ defects and left anterior descending to left ventricular fistula $\stackrel{\varnothing}{\varnothing}$ has to our knowledge never been reported.

The association of the two lesions is caused by myocardial contusion. ${ }^{5}$ Although a small ventricular septal defect may $\vec{\circ}$ close spontaneously, the treatment of choice is surgical, $\overrightarrow{\vec{C}}$ especially where there is a pulmonary:systemic blood flow $\vec{\omega}$ ratio of more than $2: 1$ and evidence of cardiac failure. If the patient is haemodynamically stable it is better to delay the $\vec{x}$ surgical closure for at least two weeks from the time of injury to allow fibrosis of the edges of the ventricular septal defect to facilitate the repair and avoid recurrences.

Experience with conservative treatment of patients with $\vec{\circ}$ congenital coronary artery fistulas suggests that even totally of symptom free patients may develop complications, such as 0 congestive heart failure and angina. Whether this could be true of traumatic fistulas is not known. ${ }^{6}$ Traumatic coronary $\vec{\square}$ artery fistula more often affects the right coronary than the

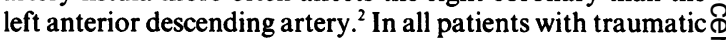
fistula, closure of the fistula should be from within the recipient chamber. In our case there was a small fistula very믐 close to the ventricular septal defect arising from a small $\vec{C}$ septal branch, and we had to assume that it was closed during $\infty$ suturing of the ventricular septal defect as it could not be. identified at surgery.

Blunt chest injuries occur frequently in modern socięy despite seat belts. Cardiac sequelae are rare but the occurrence must be suspected in any case of blunt trauma承 the anterior chest wall. Surgical correction can be done with $a \frac{2}{\mathbb{D}}$ low mortality but an accurate anatomical diagnosis is $\varrho$ necessary. Much of the information is obtained by echocar- $\overrightarrow{\overline{0}}$ diography but, as our case shows, cardiac catheterisation 3 may be necessary for more complete information.

\section{References}

1 Campbell GS, Verniez R, Varco RL, Lillehei CW. Traumatic ventricular septal defect. J Thorac Surg 1959;37:496.

2 Kirklin JW, Barratt-Boyes BG, eds. Cardiac surgery. Chichester: Wiley, 1986:1387-92.

3 Lowe JE, Adams DH, Cummings RG, et al. The natural history and recommended management of patients with traumatic $D$ coronary artery fistula. Ann Thorac Surg 1983;36:295-305.

4 Sareli P, Goldman AP, Pocock WA, Colsen P, Casari A, Barlow JB. Coronary artery-right ventricular fistula and organic tri- $G$ cuspid regurgitation due to blunt chest trauma. $\mathrm{Am} \mathrm{J} \mathrm{Cardiol}{ }_{N}$ 1984;54:697-9.

5 Jones FL. Transmural myocardial necrosis after non-penetrating $\mathbf{W}$ cardiac trauma. Am J Cardiol 1970;26:419-22.

6 Cafferkey EA, Crawford DW, Turner AF, et al. Congenital aneurysm of the coronary artery with myocardial infarction. Am J Med Sci 1969;257:320-7. 